Antigen. Damit soll, vergleichbar mit der spezifischen Immuntherapie, eine Toleranzreaktion erzielt werden. In neuen Forschungsprojekten sind allergenpräsentierende Zellen die Zielzellen dieser Therapie.

2. „Toll-like“-Rezeptor-Agonisten: "Toll-like"-Rezeptoren (TLR) gehören zum angeborenen Immunsystem und induzieren bei Stimulation durch bestimmte Keime oder Nukleinsäuren die Immunabwehr durch Makrophagen und neutrophile Granulozyten. Ein Teil dieser Rezeptoren ist jedoch auch in der Lage, die Balance des erworbenen Immunsystems im Sinn eines TH1-Shifts zu verändern. Eine Stimulation dieser Rezeptoren durch spezielle Agonisten könnte damit eine gewünschte Modulation des Immunsystems bewirken. Theoretisch mögliche schwere Nebenwirkungen wie das Auslösen von Autoimmunopathien sollten jedoch berücksichtigt werden.

3. CpG-Oligonukleotide: Bestimmte TLR (TLR 9) sind in der Lage, virale oder bakterielle DNA als Auslöser für eine Immunantwort zu erkennen. Oft sind Cytosin-Guanin-
Sequenzen $(\mathrm{CpG})$ für diese DNA charakteristisch. Mit chemisch modifizierten CpG-Oligonukleotiden könnte man entsprechende TLR stimulieren und wie bei den TLRAgonisten die Balance des Immunsystems verändern.

4. „Antisense“-Verfahren: Die Funktionsweise lässt sich am Beispiel der „small inhibitory RNA“ (siRNA) erklären, die in der Onkologie bereits in klinischen Studien getestet wird. Diese RNA ist in ihrer Basensequenz genau gegenläufig zur "Messenger“RNA (mRNA), die den Code für ein bestimmtes Protein enthält. Lagert sich die siRNA an der mRNA an, kann deren Gensequenz nicht mehr in ein Protein übersetzt werden, die Expression des Gens wird unterdrückt. Als Zielproteine sind beispielsweise Zytokine der TH2-dominierten Immunreaktion oder des nukleären Faktors NFkB denkbar. of

Reske-Kunz A. DNA-Vakzinierung. Heeg K. Toll-like-Rezeptor-Agonisten. Kirschning C. CpG-Oligonukleotid. Garn H. AntisenseStrategien als neue kausale Therapieansätze

\title{
Nehmen Allergien mit dem Alter wirklich ab?
}

B islang hält sich die These, dass Allergien mit zunehmendem Alter der Patienten rückläufig sind. Tatsächlich zeigten die Daten des Bundesgesundheits-Surveys aus dem Jahr 2001 eine fast lineare Abnahme der Sensibilisierungsraten in Abhängigkeit vom Lebensalter. Doch Priv.-Doz. Dr. Ursula Kraemer, Düsseldorf, wies darauf hin, dass nicht das Lebensalter an sich, sondern der Geburtszeitraum die Sensibilisierungsrate bestimmt: In einer Verlaufsbeobachtung von Kohorten aus unterschiedlichen Geburtsjahrgängen (Jarvis D et al. J Allergy Clin Immunol 2005; 116: 675-82) zeigte sich, dass zwar ältere Jahrgänge weniger Sensibilisierungen aufweisen als jüngere, im zeitlichen Verlauf der einzelnen Jahrgänge nimmt aber die Prävalenz keinesfalls ab, sondern tendenziell sogar eher zu.
In der Kohortenstudie SALIA wurden zwischen 1985 und 1990 mehr als 4.700 Frauen im Alter von 55 Jahren aus dem Ruhrgebiet und aus Borken initial untersucht. Die Studienteilnehmerinnen wurden dann bis zum Jahr 2008 mehrmals befragt und erneut untersucht. Es zeigte sich, dass sich die Werte für das Gesamt-IgE zwischen dem 55. und dem 75. Lebensjahr kaum änderten. Interessant war, dass sich in jedem Lebensalter allergische Erkrankungen neu manifestieren konnten. Die Studiendaten lassen aber vermuten, dass die deutliche Zunahme von Bronchialasthma im höheren Lebensalter allerdings nicht auf Atopie zurückzuführen, sondern eher durch die Feinstaubbelastung bestimmt ist.

Kraemer U. Allergische Erkrankungen im Alter-Aspekte der SALIA-Studie

\section{Auch Fliegenallergie gibt es...}

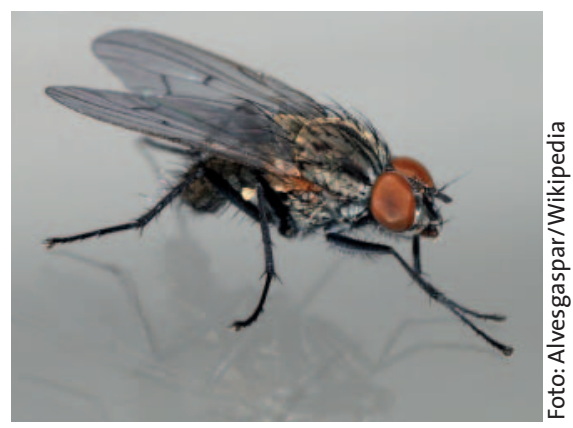

m Prinzip kann man gegen jedes Tier allergisch werden. Insektenallergie ist deshalb auch kein Synonym für Wespenund Bienengiftallergie - selbst Fliegen können spezifische IgE-Antworten provozieren und so Rhinitis und Asthma auslösen. Die Sensibilisierung erfolgt manchmal weitgehend artspezifisch. So berichtete Prof. Dr. Reinhart Jarisch, Wien, über einen 30-jährigen Landwirt, der vor allem beim Betreten der Tierställe Schnupfen und Atemnot verspürte. In Hauttest, RAST und Immunoblot ergaben sich positive Reaktionen auf Stubenfliege (Musca domestica). Die Kreuzreaktion mit der nahe verwandten Kleinen Stubenfliege (Fannia canicularis) fiel mäßig aus, mit Extrakten anderer Dipteren bestand keine Kreuzreaktivität.

Während Allergien gegen Stubenfliegen eher selten sind, führen Stechmücken bzw. ihre Speichelproteine sehr oft zu allergischen Reaktionen an der Haut. Interessanterweise werden diese oft nicht als Krankheit interpretiert, auch bei Kindern nicht, die teilweise sehr heftige und schwere Hautreaktionen zeigen. Eine ärztlich durchgeführte Mücken-Hyposensibilisierung ist wohl eher auch die Ausnahme - zumal die Toleranzinduktion offensichtlich auch unkontrolliert und unstandardisiert erfolgreich ist: Wer beispielsweise in den besonders von Mücken belasteten Gegenden Schwedens zu Beginn der Saison zunächst 100 oder gar 200 Stiche stoisch erträgt, bleibt (angeblich) für den Rest der Saison von allergischen Hautreaktionen verschont.

Jarisch R. Insektenallergie ... nicht nur auf Hymenopteren - Fliege, Mücke, Bremse 